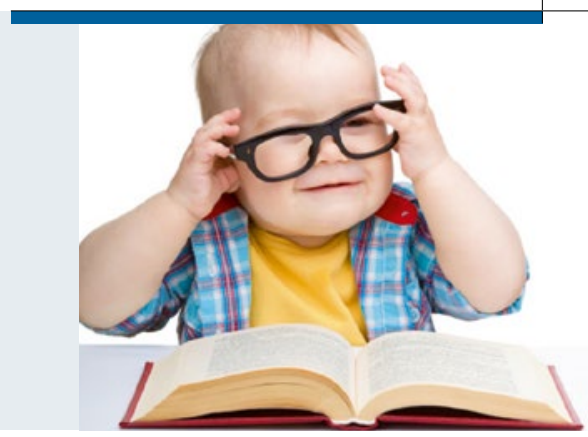

Für Eltern, Kinder und Kinderärzte

\title{
Kinderbuch-Empfehlungen
}

Diesmal zum Thema Kresbserkrankung in der Familie von Dipl.-Psych. Wiebke Claßen

\section{Leben mit der Krebserkrankung}

- Manchmal backen Mama und Lulu einen Kuchen und haben Spaß. Manchmal ist Mama müde, weil sie Brustkrebs hat. Dann versucht Lulu leise zu sein und malt ein Bild. Aber leicht ist das nicht, weil Lulu so gerne Piratin spielt und die können nicht so gut leise sein. Manchmal muss Mama ins Krankenhaus und Lulu geht zur Oma oder hat den Papa für sich allein. Lulu spielt, malt, baut Krebs-freie Zonen, erzählt Geschichten, ist mal traurig und mal wütend und alles davon darf Lulu erleben.

Warum dieses Buch? In einfacher, kindgerechter Sprache wird das Leben mit der Erkrankung erzählt. Für Kinder geht das Leben, trotz einer Krebserkrankung der Eltern weiter. Durch die Ich-Erzählung des kleinen Mädchens wird wunderbar klar, dass es o.k. ist, zu spielen und zu lachen, zu toben und zu weinen. Manchmal braucht es die Bestätigung der Eltern, dass diese unterschiedlichen Gefühle vorkommen können und dürfen. Genau das gelingt diesem Buch, auch mit Hilfe der liebevollen und klaren Illustrationen.

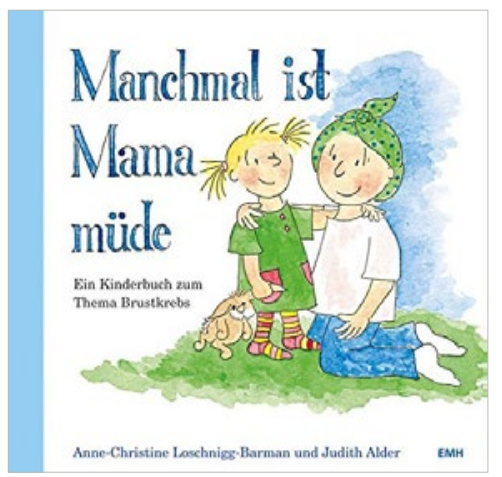

Anne-Christine Loschnigg-Barman, Judith Adler

\section{Manchmal ist Mama müde}

Ab 3 Jahren

EMH Schweizerischer Ärzteverlag 14,50 Euro

\section{Bilder und Worte für Krebs}

— Krankheit, Krebs, Bestrahlung, Chemotherapie und vieles mehr wird in diesem Buch kindgerecht, in klaren Sätzen erklärt. Am Ende jeder Seite befindet sich eine Frage zum jeweiligen Thema. Diese Frage bietet die Möglichkeit mit dem Kind ins Gespräch zu kommen, zu hören, was das Kind denkt, und eventuelle Ängste zu besprechen. Wenn sich nach einer solchen Frage ein gutes Gespräch ergibt, kann das Buch an einem anderen Tag weiter gelesen werden. Die Illustrationen sind Geschmacksache, zumindest passen sie zum Thema und bieten dem Kind Raum für Entdeckungen.

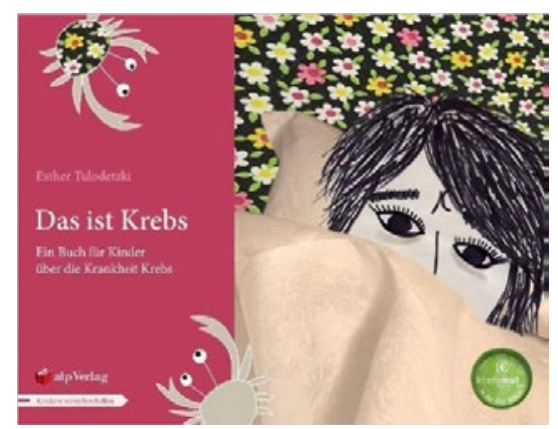

\section{Über das Thema Krebs sprechen}

- Greta und Vincent sind ein Jahr nach der Brustkrebserkrankung der Mama mit ihren Eltern im Urlaub am Strand. Die Kinder stellen viele Fragen über Krebs, Chemotherapie, Lymphdrainage und die Operation. Aber auch ihre Gedanken, warum sich die Freunde der Mutter plötzlich komisch verhalten, ob Mama wieder ganz gesund wird oder die "schwarzen“ Gedanken werden besprochen. Auch wenn das Ende offen bleibt, vermittelt das Buch Trost und Hoffnung.

Warum dieses Buch? Über das Thema Krebs zu sprechen, fällt vielen sehr schwer. Ängste, Sorgen und die Befürchtung, Kinder zu überfordern, machen es nicht leichter. In diesem Buch wird einfühlsam und ehrlich das Thema Krebs besprochen. Es macht deutlich, wie wichtig es ist, den Kindern ihre Fragen altersgerecht zu beantworten und bietet Möglichkeiten dazu an. Im Elternteil am Ende des Buches werden sinnvolle Tipps zu den Themen, "Der Begriff Krebs", "Kindergarten und Schule“, ,Veränderung und Normalität" sowie "Angst und Schuldbewusstsein" gegeben. Sehr empfehlenswert!
Ester Tulodetzki

Das ist Krebs

Ab 4 Jahren

Atp Verlag

9,80 Euro

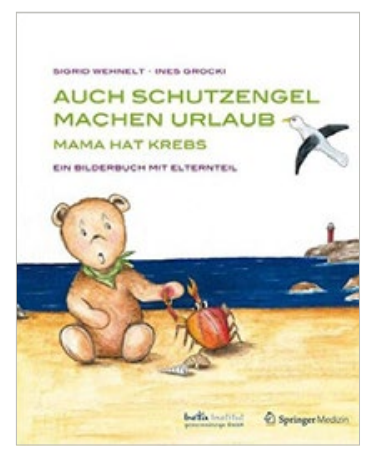

Sigrid Wehnelt, Ines Grocki

Auch Schutzengel machen Urlaub

Ab 3 Jahren

Springer Medizin 14,99 Euro 